Viso - Cadernos de estética aplicada Revista eletrônica de estética

ISSN 1981-4062

№ 6, jan-jun/2009

http://www.revistaviso.com.br/

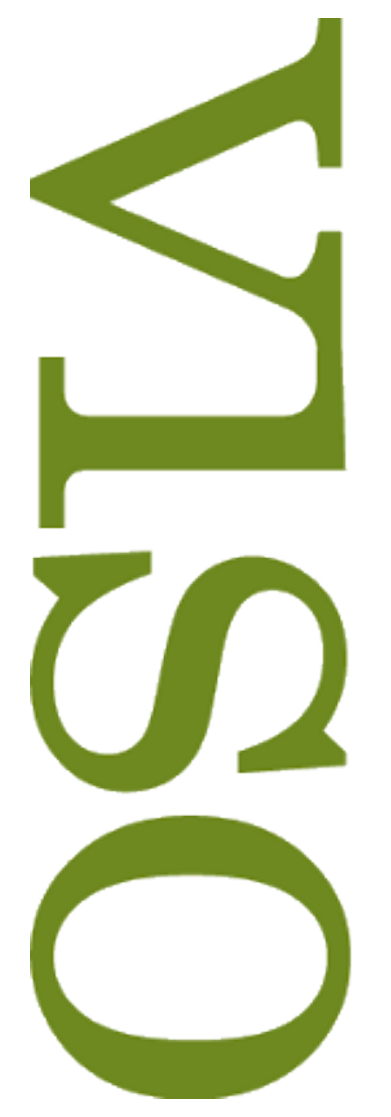

\title{
Representações do Belo no Quattrocento florentino: Leon Battista Alberti e Marsilio Ficino
}

Felipe Charbel Teixeira 


\section{RESUMO}

Representações do Belo no Quattrocento florentino:

Leon Battista Alberti e Marsilio Ficino

O ensaio analisa duas representações do belo do Renascimento Florentino, aquelas do humanista Leon Battista Alberti e do filósofo neoplatônico Marsilio Ficino.

\section{Palavras-chave:}

beleza - artes liberais - Leon Battista Alberti - Marsilio Ficino

\section{ABSTRACT}

Representations of Beauty in the Florentine Quattrocento:

The Dialectic of Enlightenment according to Pasolini and Visconti

This essay analyses two representations of the concept of "beauty" in Renaissance Florence, those of the humanist Leon Battista Alberti and the neoplatonic philosopher Marsilio Ficino.

\section{Keywords:}

beauty - liberal arts - Leon Battista Alberti - Marsilio Ficino 
CHARBEL, F. "Representações do Belo no Quattrocento florentino: Leon Battista Alberti e Marsilio Ficino". In: Viso: Cadernos de estética aplicada, v. III, n. 6 (jan-jun/2009), pp. 1-22.

DOI: 10.22409/1981-4062/v6i/68

Aprovado: 13.05.2009. Publicado: 14.07.2009.

(C) 2009 Felipe Charbel. Esse documento é distribuído nos termos da licença Creative Commons Atribuição-NãoComercial 4.0 Internacional (CC-BY-NC), que permite, exceto para fins comerciais, copiar e redistribuir o material em qualquer formato ou meio, bem como remixá-lo, transformá-lo ou criar a partir dele, desde que seja dado o devido crédito e indicada a licença sob a qual ele foi originalmente publicado.

Licença: http://creativecommons.org/licenses/by-nc/4.0/deed.pt_BR

Accepted: 13.05.2009. Published: 14.07.2009.

(C) 2009 Felipe Charbel. This document is distributed under the terms of a Creative Commons Attribution-NonCommercial 4.0 International license (CC-BY-NC) which allows, except for commercial purposes, to copy and redistribute the material in any medium or format and to remix, transform, and build upon the material, provided the original work is properly cited and states its license.

License: http://creativecommons.org/licenses/by-nc/4.0/ 
Já foi dito e argumentado que somente no século XVIII, com a Estética de Baumgarten e a Terceira crítica de Kant, a estética se torna um domínio filosófico autônomo em relação à ética e à retórica. Por essa razão, falar de uma estética do Renascimento implica tomar como ponto de partida um anacronismo, uma vez que, para os homens de letras do Quattrocento e do Cinquecento, o Bom e o Belo eram tidos como indissociáveis, embora não se confundissem plenamente - isso tanto no que diz respeito à instituição retórica e seus preceitos de conveniência e decoro, que regravam as práticas letradas e as arti liberali (arquitetura, escultura e pintura, como em definição corrente entre os florentinos), quanto às principais correntes filosóficas dos séculos $\mathrm{XV}$ e $\mathrm{XVI}$, especialmente o neoplatonismo de Marsilio Ficino, para quem a beleza se encontrava "entre a bondade e a justiça". ${ }^{1}$

Um segundo aspecto problemático envolvido na opção pela categoria estética do Renascimento diz respeito aos possíveis usos naturalizantes de um conceito surgido no século XVIII (e popularizado no século XIX pelos historiadores Jules Michelet e Jacob Burckhardt) para delimitar o período histórico compreendido entre os séculos XIV e XVI. Periodização que já em sua gênese transcendeu o aspecto puramente formal de ferramenta cognitiva: momento de "descoberta do homem e do mundo", marco zero da modernidade e de um "novo espírito", ruptura com as "trevas" medievais, o Renascimento, para falar como Leon Kossovitch, é positivado em Michelet e Burckhardt como unidade cultural, para, no fim do século XIX, ser positivado em Wolfflin como unidade estilística, momento clássico em oposição ao anti-clássico Barroco. ${ }^{2}$ Vulgarizadas, tais interpretações fizeram-se fontes das representações predominantes sobre o suposto "conteúdo imanente" do Renascimento, condensadas em rótulos como antropocentrismo, individualismo, racionalismo e classicismo.

Embora a rigidez de tais formulações oitocentistas tenha sido problematizada ao longo do século XX por importantes historiadores da arte e da cultura como Aby Warburg, Erwin Panofsky, E. H. Gombrich, Johan Huizinga, Paul Oskar Kristeller, Eugenio Garin, Quentin Skinner e outros, faz-se necessário, em função das interpretações arraigadas no senso comum, tecer alguns esclarecimentos sobre o uso que faço nesse texto do conceito de Renascimento.

Seu emprego é heurístico, em dois sentidos diversos, porém complementares: (a) como recorte temporal correspondente aos séculos XIV, XV e XVI, sem que se atribua a tal período as "qualidades" a ele normalmente associadas, como "berço da modernidade", "marco zero do individualismo", "racionalização", entre outras; (b) no sentido de rinascita, como em Vasari, renascer da Antiguidade após a media aetas, retorno a um ponto de origem sem expectativa de progresso ascendente, mas sustentado numa circularidade assimétrica de formas, costumes e instituições. ${ }^{3}$ São esses os sentidos de Renascimento que estão em jogo na proposta de examinar as representações do belo nos séculos $\mathrm{XV}$ e $\mathrm{XVI}$ em Florença, mais precisamente duas dentre inúmeras representações, em que 
filosofia, ética, retórica e poética se cruzam tanto na teoria quanto na práxis dos artífices: na compreensão da beleza como proporção, equilíbrio e decoro, como formulada em meados do século XV por Leo Battista Alberti (1404-1472), emulando autoridades latinas como Cícero, Quintiliano e Vitrúvio, e na idéia de beleza espiritual e divina desenvolvida pelo "filósofo, médico e teólogo" Marsilio Ficino (1433-1499) nos últimos decênios do século XV.

Além de se referirem a momentos distintos do humanismo florentino, trata-se de concepções diferenciadas sobre o modo de pensar a articulação entre o Bom, o Belo e o conveniente. Se analisadas em perspectiva, comparativamente, tornam possível o exame, ainda que parcial, daquilo que o historiador da arte Robert Klein chamou de "descoberta definitiva do temperamento artístico", por meio da "afirmação de que o caráter pessoal da obra pode ser um valor". ${ }^{4}$ Aqui, o evitado anacronismo pode reaparecer como tentativa de se traçar um quadro diacrônico e evolutivo a "apontar", no Renascimento, concepções modernas sobre a arte, ainda que incipientes; mas não é essa a intenção, pelo menos não completamente. Empregado com precaução (sem teleologia, sem reduzir a diferença a estágios do Mesmo), o anacronismo pode se mostrar ferramenta de inegável valor cognitivo, capaz de iluminar e propiciar a compreensão de algumas mudanças significativas nos critérios de juízo e gosto no século $\mathrm{XV}$, em Florença - logo, ao entendimento do que vinha a ser o Belo em sua relação com o Bem e o conveniente -, mudanças essas que não passaram ao largo dos artífices e litterati do Quattrocento e do Cinquecento, embora só tenham sido conceitualizadas em meados do século XVI pelo pintor e homem de letras aretino Giorgio Vasari (1511-1574).

Provavelmente a concretização mais notável da unidade, sempre almejada pelos humanistas, entre teoria e prática - a ponto de ambas se tornarem indistinguíveis na práxis dos artífices -, as arti liberali, que nos séculos XIV, XV e especialmente XVI conquistaram uma dignidade toda especial, não deixavam de constituir ragionamenti silenciosos sobre as possibilidades quase ilimitadas da imitatio, seja da natureza ou dos grandes artífices "antigos e modernos", até o ponto em que se chega a cogitar a possibilidade de superação da própria natureza (o que, de acordo com Vasari, teria sido alcançado por Michelangelo). É tentador enxergar na pintura, escultura e arquitetura do Renascimento vários inícios: a idéia de progresso artístico, o realismo, a moderna noção de gênio. O estudo dos tratados sobre as arti liberali publicados na Itália dos séculos XV e XVI (não foram muitos) permite, contudo, problematizar a teleologia explícita ou mais sutil de tais abordagens. Focar exclusivamente na questão do progresso técnico ${ }^{5}-$ aperfeiçoamento dos modos de imitação do real, como nas tão celebradas invenções da perspectiva (por Brunelleschi e Alberti) e aprimoramento do desenho (por Leonardo da Vinci) -, e na suposta competição entre "artistas" pelo cálice sagrado da representação fiel das coisas mesmas, é abordar apenas um lado da questão, e mesmo assim de modo um tanto turvo. 
A própria noção de progresso não possuía então as acepções de linearidade e movimento ascendente - falava-se no progresso dos males e dos bens. Havia, isto sim, uma idéia de ciclos das artes, desenvolvida e teorizada nas Vidas de Vasari, publicadas inicialmente em 1550 e aumentadas na segunda edição de 1568. No proêmio ao livro II, o pintor aretino defende que as arti liberali, como todas as coisas humanas, estariam sujeitas a ciclos de ascensão e queda. Tal noção de ciclos consiste na aplicação para a pintura, a escultura e a arquitetura de uma lógica bastante aceita no mundo antigo e no Renascimento, fundada numa cosmologia alicerçada na distinção entre uma esfera celeste, sempre igual a si mesma, e uma esfera sublunar, suscetível a ciclos diversos e transformações. Todas as criações humanas, como cidades, formas de governo e costumes, deveriam seguir ciclos análogos aos movimentos da natureza. Uma vez alcançado o ápice, seria de imaginar a corrupção e degradação, em função da instabilidade atribuída às coisas humanas. ${ }^{6}$ É o que teme Vasari: "a arte alcançou tudo o que podia ser feito na imitação da natureza, e ela chegou tão alto que mais se pode temer um retrocesso que esperar novos avanços". ${ }^{7}$ Logo, o que historiadores da arte contemporâneos como E.H. Gombrich identificam com a idéia de progresso não era senão uma forma bastante arraigada de pensar a dinâmica das "coisas do mundo". Nesse ponto, revela-se a importância de examinar as práticas artísticas do Renascimento a partir do critério do verossímil histórico ${ }^{8}-0$ que tais práticas podem ter significado para os homens dos séculos $\mathrm{XV}$ e XVI, segundo costumes e preceitos de ampla circulação e difusão cultural.

É o caso, por exemplo, dos diversos mecanismos intelectuais de pensar a natureza do Belo e sua relação com o Bem, e sobretudo os modos com que tais concepções se fazem presentes, mesmo que de forma aparentemente imperceptível aos hermeneutas modernos, nas pinturas, esculturas e projetos arquitetônicos do Renascimento. Revelase, de tal modo, a centralidade de categorias como engenho, maneira, invenção e ornato, abundantes nos tratados sobre as arti liberali dos séculos XV e XVI (enquanto outras como gênio e progresso praticamente não se fazem presentes), efetivas ferramentas conceituais para pensar e urdir a convergência, num todo orgânico, do Belo, do Bem e do conveniente. Este texto tem por horizonte o exame de dois modos distintos de compreender, de forma honesta e honrosa, a beleza em sua acepção ética, mas também retórica (a retórica é certamente mais importante em Alberti que em Ficino, embora não deixe de se fazer presente no filósofo neoplatônico). Trata-se de ragionamenti distintos sobre o fazer "artístico", sobre a "função" das arti liberali, se é que se pode falar de função nesse contexto, especialmente os modos com que estas, em todos os seus movimentos, refratavam decoros, hierarquias humanas e celestes, concepções tácitas sobre a vida civil, entre outros aspectos. A maniera e o temperamento do artífice não podem, desse modo, ser compreendidos exclusivamente pelo viés psicologizante; tampouco se busca reduzir a arte a epifenômeno, ou traçar retratos sincrônicos que desconsiderem as significativas transformações por que passaram as arti liberali entre os séculos XIV e XVI. 
Toda a argumentação é construída a partir dessa polaridade operatória: por um lado, a tentativa de traçar verossímeis históricos coerentes com as práticas e costumes letrados e "artísticos" circulantes entre os florentinos do Quattrocento e do Cinquecento; por outro, o desejo de interpretar diacronicamente algumas transformações conceituais realizadas, ainda que não necessariamente de forma consciente, em textos dos mais diversos gêneros, voltados, direta ou indiretamente, às arti liberali, ou para a definição e compreensão do Belo, assim como as contínuas modificações, estas sim refletidas e arrazoadas, nas práticas dos artífices. Tal esforço deveria incluir o exame de outros homens de letras, além de Alberti e Ficino, especialmente Ghiberti, Vasari e Lomazzo, mas o tempo, o espaço e o estado atual da pesquisa não permitem esse aprofundamento. Expondo e analisando dois modos distintos de pensar o Belo, sua relação com o Bem e seu lugar nas arti liberali, pretendo lançar algumas perguntas (e nenhuma resposta) acerca do imperioso problema da valorização crescente, ao longo do Renascimento, da singularidade dos artífices.

II

Retratado por Jacob Burckhardt em meados do século XIX como uma espécie de modelo do "homem universal", precursor imediato de Leonardo, sujeito de inúmeras aptidões - arquiteto, pintor, literato, estudioso da matemática e da física, músico, orador de rara eloqüência, homem cultivado e discreto ${ }^{9}$-, o florentino Leon Battista Alberti (1404-1472) foi considerado por diversas tradições interpretativas uma espécie de síntese dos valores culturais do Renascimento e do Humanismo. ${ }^{10}$ Trata-se de imagem coerente com o retrato sincrônico do Renascimento pintado por Burckhardt - nascimento do indivíduo, formação espiritual do homem moderno -, mas também com uma certa flexibilização deste retrato, no sentido de realçar uma forma de subjetividade supostamente corrente em uma época de perda da segurança existencial e reveses imprevisíveis da Fortuna. "Interpretação histórica que a seu tempo seduziu muitos de nós" ${ }^{\text {, }}$, atesta Eugenio Garin, a noção burckhardtiana de individualismo é problematizada e revista por meio do exame dos modos de lidar com aquilo que o historiador italiano chama de "obscura consciência de um final"12: o esvaziamento da segurança ontológica típica do medievo; os limites entre livre-arbítrio e contingência; a ausência de orientações pré-determinadas, modelos normativos de validade indistinta.

O Renascimento, nesse sentido, é pintado como "entre-lugar" de experiências fronteiriças sempre em choque - o velho e o novo, o recorrente e o inaudito. Diz Garin que "se nos detivermos numa posição típica como na de Alberti, grande erro seria [...] se nessa 'virtude' víssemos apenas a pura certeza do construtor, seguro do seu modo de fazer, que não se sente continuamente ao lado de um perigo". E conclui: "Exatamente porque é sempre poeta, isto é, criador, Alberti está bem consciente de todo o risco que implica a criação, a construção real, que seja uma mudança dos fundamentos da totalidade do dado, o mundo com que nos defrontamos". ${ }^{13}$ Contraponto do Alberti senhor de todos os seus movimentos, Garin erige a imagem de um homem "pessimista", "triste", 
capaz de reconhecer os poderes da Fortuna sem se curvar a ela ou resignar-se diante dos seus caprichos. $^{14}$ Ele, contudo, considera que a disparidade entre suas representações de Alberti e aquelas celebrizadas por Burckhardt (diversidade que parece ser traçada pelo historiador italiano não como oposição de extremos, e sim como fronteira porosa) pode ser compreendida menos como "consciência de que a segurança tranqüila [...] está definitivamente perdida"15 (uma espécie de aguçamento subjetivo da sensibilidade trágica diante de mudanças normativas objetivadas ontologicamente) do que como produto da necessidade de adequar retoricamente a invenção e o engenho aos decoros dos diversos gêneros letrados.

A bem da verdade, já em seu tempo, ou ao menos um século depois de sua morte, Alberti era tido como espécie de símbolo; não, porém, de uma certa idéia de Renascimento, ou de interpretações conflitantes sobre o Renascimento, unidade cultural impregnada de valores constitutivos e estruturantes, sejam eles quais forem. Nas Vite de'più eccellenti pittori scultoti ed architettori de Giorgio Vasari, Alberti não é elogiado apenas por suas habilidades de arquiteto e pintor. Se é emblema, e é evidente que assim sua imagem é composta, Alberti o é do humanismo. Não do "humanismo cívico" de Hans Baron $^{16}$, tampouco do humanismo filosófico - filosofia universal do homem - como em Ernst Cassirer. Talvez emblema do que pode ser alcançado por meio da combinação entre aptidão natural e studia humanitatis (estudo detido do que diziam e prescreviam as autoridades antigas acerca da retórica, gramática, história, poesia e filosofia moral ${ }^{17}$; certamente, emblema da unidade sempre desejada, e quase nunca alcançada, entre teoria e prática.

A educação florentina do século $\mathrm{XV}$, emulando autoridades antigas, valorizava sobremaneira o estudo literário, mas em sentido distante do que se convencionou denominar, modernamente, de aquisição de "cultura geral". ${ }^{18}$ Pode-se dizer que os escritos humanistas sobre a educação dos jovens alicerçavam-se tanto na indissociabilidade entre ética e retórica como na defesa da complementaridade entre prática e teoria, vida ativa e vida contemplativa - o que se pode perceber na leitura de escritos do Quattrocento voltados à formação dos jovens.

Em texto da década de 1420, Leonardo Bruni atribui grande relevo à leitura, meditação e imitação dos textos antigos, assim como à instituição retórica: "aqueles que desejam alcançar a excelência [...] devem possuir antes de tudo perícia não pequena nem vulgar nos estudos literários, mas grande e constante e acurada e profunda". ${ }^{19}$ Esperava-se que o estudo nutrisse a alma a partir de bons modelos, emulados na composição de peças letradas e na própria conduta nos espaços citadinos. ${ }^{20}$ Por essa razão, segue Bruni, o estudante deve se ater apenas aos "livros dos ótimos escritores latinos, guardando-se distância, porém, dos livros redigidos de forma rude e grosseira, calamitosa ruína do nosso engenho". ${ }^{21}$ Os bons exemplos produzem o efeito de aguçar o engenho; os maus exemplos podem até mesmo arruiná-lo. 
O contato com as "boas letras", todavia, era considerado pouco útil se não fosse complementado por uma apropriada scientia rerum, conhecimento das "coisas do mundo" - dito de outro modo, experiência. O tom é ciceroniano, e remete à noção do orador pleno, eloqüente não apenas por dominar técnicas persuasivas e modos elocutivos e dispositivos, mas também, e necessariamente, pelo conhecimento profundo da matéria tratada, rerum cognitione. ${ }^{22}$ Antes mesmo de Bruni, o propósito ético dos studia humanitatis já havia sido enfatizado no início do século XV por Pier Paolo Vergerio em De ingenuis moribus: "é naquela idade verde, logo, que devem ser inculcados os fundamentos de todo o nosso viver, e acomodar a alma à virtude". ${ }^{23}$

No mesmo espírito de Vergerio, Bruni e outros humanistas, Vasari, no capítulo de suas Vidas dedicado a Alberti, faz o elogio dos pintores, escultores e arquitetos que recorrem às "boas letras" para "ornar e aguçar a invenção que naturalmente nasce com eles". ${ }^{24}$ Trata-se, segundo ele, de recurso "útil e necessário" ao "engenho miraculoso destes artífices", isto porque "o juízo nunca é tão perfeito em uma pessoa" ${ }^{25}$ a ponto de a experiência dispensar a educação literária. Se algumas das categorias empregadas por Vasari - como invenção, engenho, ornato e juízo - reforçam a dependência conceitual do discurso sobre as arti liberali da instituição retórica, também o elogio da unidade entre teoria e prática pode ser lido nessa chave: "mas quando é o caso de ambas [teoria e prática] estarem juntas por sorte, é coisa muito conveniente à nossa vida, isto porque a arte, com o meio da ciência, torna-se muito mais rica e perfeita". ${ }^{26}$

Vê-se, na passagem de Vasari, que a complementaridade entre buone lettere e ingegno era tida como algo muito difícil de alcançar. Algumas décadas antes, Francesco Guicciardini advertira, em seus Ricordi: "Como diferem a prática e a teoria! Quantos são os que entendem bem as coisas, mas que ou não se recordam ou não sabem pô-las em ação. Aos que agem assim, esta inteligência é inútil, porque se assemelha a ter um tesouro em uma arca com a obrigação de não poder jamais tirá-lo fora dela". ${ }^{27}$ Alberti teria sido, assim, um dos poucos que soubera ao mesmo tempo cultivar o tesouro e tirálo de sua arca, em tratados de grande reputação sobe a arquitetura, a pintura e a escultura, assunto sobre os quais, argumenta Vasari, "nenhum dos artífices modernos havia conseguido escrever, ainda que muitos o tivessem superado na prática". ${ }^{28} \mathrm{O}$ segredo de Alberti, o que o torna digno de elogio, de acordo com Vasari, foi ter escrito sobre as realizações dos artífices aliando conhecimento de causa, rerum cognitione, e eloqüência, ratio dicendi, atingindo assim o ideal ciceroniano do orador pleno. Ainda mais importante: ambas, conhecimento da matéria e arte de dizer, se enlaçam ao ponto de tornarem-se indistinguíveis. Daí a dignidade e fidúcia atribuída aos livros: seus escritos sobre as arti liberali teriam acrescentado muito ao "nome e à fama" de Alberti, isto porque, em relação à pintura, "os escritos possuem maior força e vida, visto que os livros comodamente chegam a todos, e neles todos dão fé, com a condição de que sejam verdadeiros e sem mentiras". ${ }^{29}$ 
A dignidade dos escritos associa-se deste modo à própria dignidade de quem os compõem - a persuasão pelo ethos, como define Aristóteles em sua Retórica. Mas esta, por si só, não é suficiente, embora seja importantíssima. Para que o autor obtenha fé, é preciso que se dê uma adequação entre produção textual e expectativa de sentido. Os efeitos são controlados, e devem dar o mínimo de margem à "diversidade de leituras". Atendo-se ao que convém - e o que convém é normatizado em preceptivas, de acordo com o auditório, a hierarquia social e o gênero retórico -, produzindo decoros com seu engenho aguçado, emulando autoridades reconhecidas e aceitas, o homem de letras erige a arquitetura da sua própria glória e dignidade. Como afirma Cícero no Orator, "da mesma forma que na vida, também nos discursos o mais difícil é ver o que convém". Para que isso seja possível, "o orador deve mirar o conveniente não só nas idéias, mas também nas palavras". ${ }^{30}$ Porém, para alcançar plenitude discursiva, copia dicendi, é preciso que o homem de letras faça convergir conhecimento da matéria e decoro letrado, sem o qual o discurso será vazio, e inverossímil porque não convincente; logo, indecoroso mesmo no que diz respeito à ars dicendi. Ainda mais importante: conhecimento da matéria e arte de dizer devem se imbricar, conformando uma unidade. Só assim o decoro letrado pode educar o leitor na virtude da prudência, como defendiam os humanistas Coluccio Salutati e Giovanni Pontano. ${ }^{31}$

Esta teria sido a maior aquisição de Alberti, de acordo com Vasari, o que imortalizou seu nome, mais que suas pinturas ou projetos: o decoro capaz de moldar a prudência e o engenho de artífices dotados de aptidão natural quase incomparável. ${ }^{32}$ Se com as boas letras ele moldava o próprio engenho, ao compor tratados ricos de preceitos éticoretóricos ele teria contribuído para o aprimoramento do engenho, juízo e prudência de muitos outros artífices, alterando fundamentalmente a própria compreensão do que se convencionou tomar, desde a Antigüidade, como razão de ser das arti liberali: a imitação da natureza. E isto não apenas pela reflexão sobre a técnica da perspectiva, surgida com Brunelleschi e teorizada pela primeira vez pelo próprio Alberti ${ }^{33}$, aspecto tão valorizado modernamente, mas que, como lembra Leon Kossovitch, deve ser compreendido como parte de um amplo discurso sobre a composição pictórica, e não como excurso independente. ${ }^{34}$ Fundamentalmente, pela ênfase atribuída à história, ou ao aspecto intelectual envolvido na produção pictórica, "a maior obra que um pintor pode fazer", diz Alberti em Da Pintura, "não é uma estátua tão grande quanto um colosso, mas uma história, visto que se encontra maior elogio do engenho em uma história que em um colosso". ${ }^{35}$ É em função da história que a obra se mostra "verdadeira e perfeitamente acabada". A história é composta pelos corpos; estes, pelos membros; e os membros, pela superfície. A história corresponde exatamente no modo como são ordenados, dispostos e compostos os corpos.

Embora o preceito de que as artes deveriam imitar a natureza não seja questionado, não se deve compreender a imitatio em Alberti como simples cópia descritiva da realidade. ${ }^{36}$ Trata-se, mais precisamente, de procedimento prudencial de conhecimento das "coisas do mundo", envolvendo inventio, dispositio e elocutio - escolha do que dizer a partir de 
um vasto repertório, assim como dos modos de dizer, disposição harmônica das partes, e "entrega", o dizer ornado -, as quais são adaptadas à pintura como circunscrição, composição e recepção de luz. Como nota Carlos Antonio Leite Brandão, "é na compositio", a parte da pintura correlata à dispositio retórica, "que a História é construída, compondo as várias partes da pintura numa totalidade submetida aos efeitos pretendidos pela historia". ${ }^{37}$ Assim, "da mímesis do mundo fenomênico passa-se à do mundo moral. Simetricamente, a jusante da cena representada, os corpos pintados fazem a historia dirigir-se à alma e não aos olhos do espectador".

Segundo palavras de Giulio Carlo Argan, a "arte", em Alberti, constitui "processo de conhecimento cujo fim não é tanto o conhecimento da coisa quanto o conhecimento do intelecto humano, da faculdade de conhecer". A própria perspectiva, nesse sentido, deve ser compreendida menos como um "avanço técnico nos modos de reprodução da realidade" ${ }^{\prime 3}$ que como invenção do espaço, unidade de diversos modos de visão possíveis. Nesse sentido, ainda segundo Argan, a perspectiva "não fenomeniza a realidade como fenômeno em si, mas fenomeniza a realidade como pensada pela mente ou, em outras palavras, a mente humana que pensa a realidade na unidade fundamental dos seus aspectos" ${ }^{39}$ Isto posto, quando Alberti discorre sobre a pintura, não se tem um discurso puramente "técnico", exposição desadornada das regras da arte. Muito pelo contrário: "a história", diz o humanista florentino, "merecedora de elogio e admiração, deverá, com seus atrativos, demonstrar ser de tal modo agradável [dilettevole] e ornada a ponto de cativar longamente, com prazer e deleite da alma, os olhos daqueles que são e daqueles que não são [conhecedores das 'regras da arte']". ${ }^{40}$ Trata-se de um olhar educado segundo decoros e conveniências que devem ser construídos, para empregar vocábulo notabilizado por Castiglione em $O$ cortesão, com sprezzatura, uma negligência diligente capaz de produzir efeito de graça, leveza e harmonia, encobrindo e mascarando o artifício.

Assim como a retórica, a pintura deve deleitar, mover e ensinar. ${ }^{41}$ Deleitar pela copia e varietà delle cose, pela construção proporcional dos membros, pela variedade dos corpos e dos edifícios, pelo equilíbrio das superfícies, das sombras e claros, do preto e do branco, sempre tendo por horizonte o modelo máximo, a natureza: "na composição das superfícies", afirma Alberti em Da Pintura, "é preciso indagar grandemente sobre a graça e a beleza. Mas de que modo podemos chegar a isso, não encontrei método mais certo que observar a natureza mesma", pois "a natureza, maravilhosa artífice das coisas, compôs as superfícies em belíssimos membros. Ao imitá-la é preciso exercitar-se com todos os nossos pensamentos e diligência" ${ }^{42}$ Porém, na medida em que a imitatio não se confunde com a cópia fenomênica do real, não se pode dizer que os juízos de Alberti sobre a organização, o emprego das cores, a definição de modelos, etc. sejam preceptivas sobre a organização "formal" da pintura. Isto porque o deleite não será alcançado se a história não refratar hierarquias ou virtudes, se não for capaz de mover na direção do bene beateque vivendum. ${ }^{43}$ 
A beleza, nesse sentido, é o produto da unidade harmônica e graciosa entre composição, circunscrição e recepção da luz, por um lado, e a clareza, dignidade e conveniência da história por outro lado, segundo o critério da justa medida. Não basta ser fiel à natureza; é preciso, a partir da visão, construir prudencialmente o belo, produzir artificialmente harmonia e graça, a partir de duplo movimento: o trabalho intelectual e a execução apropriada. ${ }^{44} \mathrm{O}$ belo, assim, não é produto exclusivo de uma técnica apurada, embora sem ela não haja possibilidade de representação verossímil. A harmonia e a graça só podem se manifestar na medida em que a obra seja capaz de mover e ensinar, de acordo com a virtude e os preceitos de conveniência tomados como critérios quase normativos, sendo indissociáveis do útil, do honesto e do conveniente - inclusive encobrindo a própria técnica empregada, num tipo de "realismo efeitual", ou efeito de real, em que as partes envolvidas reconhecem a agudeza do engenho na medida em que este se torna invisível como sprezzatura.

A questão do temperamento, do caráter pessoal da obra, não é assim colocada, o que não significa desconsiderar o esforço intelectual de composição. Muito pelo contrário: este se faz ver no duplo movimento de aprimorar e encobrir o artifício, de privilegiar a história sem didatismo, de construir a realidade como imitatio. Coloca-se, assim, o problema da maniera, como percebeu com agudeza Vasari em meados do século XVI, ao analisar as pinturas de Masaccio. Esta, porém, afirma-se por meio da própria invisibilidade, o que exige esforço redobrado, construir e encobrir: desejar a fama, aprimorar-se e a ponto de dar a ver a realidade como realidade, para assim ter o próprio engenho reconhecido. "E quanto às boas maneiras das pinturas", diz Vasari, "deve-se maximamente a Masaccio [o verdadeiro método de visar o grau supremo], por ter ele, em seu desejo de conquistar fama - e não sendo a pintura outra coisa que não a imitação de todas as coisas da natureza viva como por esta são produzidas, simplesmente com o desenho e o colorir -, considerado que aquele que isto consegue de forma mais perfeita, deve ser considerado excelente". ${ }^{45}$ Daí que "as coisas feitas antes dele podem ser chamadas de pintadas, e as suas vivas, verazes e naturais". ${ }^{46}$ Nesse sentido, diz Vasari, Masaccio foi inventore ${ }^{47}$, mas não na acepção moderna de alguém que se distingue dos outros por imprimir o próprio gênio na arte, mas no sentido retórico de inventio: descoberta do que dizer a partir de lugares-comuns, argumentos-ripo (topoi), lugares estes que, em Masaccio, nada mais são que os sítios da natureza, "maravilhosa artífice das coisas", como dizia Alberti.

Trata-se assim de representação objetiva, no sentido de uma objetividade igualada às propriedades materiais e imateriais das coisas mesmas, necessariamente visíveis, mas não de fotocópia, isto porque a composição de um quadro, de uma escultura, ou o projeto de um prédio é, em todos os seus momentos, pensada como mecanismo, consciente ou não de por em jogo valores éticos, retóricos, teológicos, políticos e cosmológicos. É nesse sentido que, penso eu, pode ser interpretada a aguda afirmação de Argan acerca de Masaccio: "assim como na natureza não existem um belo e um feio, na ordem ética não há um bem e um mal dados a priori: o que vale é sempre e somente 
a realidade, o único juízo possível é o de real e não-real". ${ }^{48}$ Aprimorar tecnicamente o modo de representação é antes de tudo um dever ético; não se trata apenas, e nem preferencialmente, de afirmar o próprio engenho como superior, mas de buscar a fama e a glória por meio de um compromisso com a verdade das coisas - e fico tentado a dizer verità effetuale della cosa, como em Maquiavel -, verdade efeitual das coisas como são vistas (em efeito) pelo artífice, com um olhar educado na busca da harmonia, do equilíbrio, da concórdia e do decoro - um olhar que espelha na realidade tais valores, se espelha nesse espelho, e constrói a realidade representada como harmônica e decorosa. O engenho assim não é fim, mas meio, dádiva que deve ser retribuída na produção da Beleza.

III

Fundador da Academia Platônica em Florença, sob os auspícios de Cosimo e Lorenzo de' Medici, o humanista Marsilio Ficino (1433-1499) alcançou reputação em seu tempo por sua atividade como médico, homem de letras e filósofo. Tradutor de Platão e Plotino, autor de tratados sobre a astrologia e a saúde dos homens de letras, Ficino notabilizouse sobretudo pelo monumental projeto da Theologia Platonica, tentativa de fundir a filosofia do filósofo ateniense com preceitos bíblicos. ${ }^{49}$ Antes disso, em De Amore, comentário ao Banquete de Platão, ele já esboçara o projeto de uma articulação entre ensinamentos cristãos e pagãos, com base em cosmologia complexa, alicerçada não apenas em fundamentos bíblicos e platônicos, mas também em escritos então atribuídos a Hermes Trimegisto, supostamente um egípcio lendário, autor de tratados mágicos e cosmológicos antiqüíssimos como o Asclépio e o Pimandro, ambos traduzidos por Ficino para o latim - tratava-se, na realidade, sem que Ficino o soubesse, de textos de inspiração neoplatônica dos séculos II e III d.C. ${ }^{50}$

São quatro, para o filósofo florentino, as hierarquias do universo, que giram em torno de Deus, centro do círculo, com perfeição decrescente ${ }^{51}$ : a Mente, região estável e incorruptível, se bem que múltipla, "por conter", como afirma Erwin Panofsky, "as idéias e as inteligências (anjos) que são os protótipos de tudo o que existe nas zonas inferiores"52; a Alma, "região de puras causas", mundo celestial; a Natureza, mundo terrestre, sublunar; finalmente, a Matéria, sem vida e amorfa. O universo de Ficino não é estático: encontra-se em constante movimento, sendo uma espécie de "divinum animal", onde uma "corrente contínua de energia sobrenatural espalha-se de cima para baixo e regressa de baixo para cima, formando assim um circuitus spiritualis". ${ }^{53}$ Deus, o centro de tudo, confunde-se com o próprio Bem; já a Beleza, nas palavras de Ficino, "é o raio de Deus, infuso nos quatro círculos que giram em torno de Deus". ${ }^{54}$ Nos quatro círculos encontram-se todas as coisas que são - ou, melhor dizendo, as "espécies dessas coisas": as idéias, na Mente Angélica; razões, na Alma; sementes, na Natureza e formas, na Matéria. ${ }^{55}$ 
De acordo com essa lógica, a Beleza é definida precisamente como poder de atração exercido pelo Centro sobre os Círculos, estando assim diretamente relacionada ao Amor, desejo de capturar a beleza mundana, e ao Prazer, união com a Beleza Universal. ${ }^{56}$ Ficino opõe-se, deste modo, ao entendimento amplamente disseminado no Renascimento florentino de que a beleza equivaleria à "posição correta de todos os membros, verdadeiramente em igualdade de medida e proporção, com alguma suavidade de cores" ${ }^{57}$ Assim como Plotino, para quem a equiparação do belo com o simétrico não se mostrava capaz de evitar a aporia de considerar bela a concordância entre coisas más ${ }^{58}$, Ficino defende que a beleza não é corpórea; mesmo os corpos chamados de belos não o são pela sua condição de matéria. ${ }^{59}$ À Alma, argumenta Ficino, só é agradável a beleza por ela percebida. ${ }^{60} \mathrm{~A}$ beleza incorpórea, define o filósofo, "é a que agrada, e o que agrada é apreciado, e o que é apreciado é belo. Donde se conclui que o amor se refere à coisa incorpórea, e a beleza é mais uma similitude espiritual da coisa que beleza corporal". ${ }^{61}$

A concepção de beleza em Ficino mostra-se devedora, naturalmente, da teoria platônica das Idéias. Como argumentou Erwin Panofsky em seu estudo sobre a "evolução do conceito de belo", para Ficino "também a Idéia do belo está impressa em nosso espírito como uma 'fórmula', e é somente essa noção inata que confere a nós, ao que há de 'espiritual' em nós, a faculdade de reconhecer a beleza visível e de julgá-la em função de uma invisível beleza e saboreando o triunfo, tal como nela se manifesta, do 'eidos' sobre a matéria; bela é a coisa que, na terra, está em harmonia mais completa com a Idéia da beleza (e ao mesmo tempo com sua idéia própria), e reconhecemos essa harmonia relacionando a aparência sensível à 'fórmula' conservada em nós". O que, ainda segundo Panofsky, difere completamente do conceito de beleza em Leon Battista Alberti, o qual "deixa transparecer [...] uma acusação vigorosa contra os que se julgam capazes de fazer obra bela sem estudar a natureza". ${ }^{62}$

Assim, se para Alberti as grandes realizações dos artífices resultavam da união entre engenho natural, domínio das técnicas de composição e decoro, em emulação da própria Natureza (sem que a imitatio se reduzisse a simples cópia bruta), em Ficino o engenho não se dissocia do temperamento, isto porque a disposição corporal dos humores, com predomínio da bile negra não adusta, confere certos atributos favoráveis à percepção intelectiva das Idéias, numa atração simpática mútua entre o humor melancólico e o centro de todas as coisas. Nesse ponto, o filósofo florentino segue tanto Aristóteles em seu Problema XXX,1 como a discussão platônica sobre o furor divino. É diante desse quadro conceitual que se pode compreender a atribuição ao Amor do epíteto de mestre de todas as artes: "entendemos assim que [o amor] seja mestre de todas as artes, se considerarmos que ninguém pode encontrar ou aprender arte alguma, se não se move pelo prazer de buscar procurar o verdadeiro, e se quem ensina não ama os discípulos e se os discípulos não possuem amor à doutrina". ${ }^{63} \mathrm{O}$ amor ao verdadeiro, a atração direcionada ao transcendente deve mover os artífices das diversas artes - a pintura, a escultura, a arquitetura, mas também a medicina, a música, a ginástica, entre outras - 
como uma espécie de Sol, o Bem, capaz de atrair para si todas as atenções; a beleza produzida pelo artista nada mais é que um equivalente desse raio divino emanado, raio este que traz consigo a propriedade de fazer ver a verdade para além do mundo fenomênico. A beleza, assim, não está propriamente nas coisas, tampouco nos "olhos de quem vê", mas no efeito da Idéia em alguém, algo que somente um artífice iluminado, em seu furor divino, é capaz de produzir. É nesse sentido que se pode articular a retórica à questão do belo e do amor em Ficino.

Em Saturno e a melancolia, livro redigido por Raymond Klibansky, Erwin Panofsky e Fritz Saxl ao longo das décadas de 1920 e 1930, e publicado apenas em 1964, os autores analisam o suposto nascimento da idéia moderna de gênio nos escritos de Ficino. ${ }^{64} \mathrm{Ao}$ identificar e fazer convergir quatro "tradições" distintas de pensamento - a saber, (a) a melancolia produtiva aristotélica, (b) o furor divino platônico, (c) a teoria clássica dos humores e temperamentos e (d) as representações astrológicas sobre os poderes de Saturno -, Ficino, segundo os autores, teria aberto o caminho para a compreensão da melancolia como força intelectual positiva e condição natural do gênio de homens diferenciados. Vejamos o que diz Ficino: "os sacerdotes das Musas", afirma ele em De Vita Sana, primeiro dos três livros que compõem o De Vita Libri tres, estudo destinado à saúde dos homens de letras, "são melancólicos por natureza, ou se tornam melancólicos pelo estudo [...], o que se confira no livro Problematum de Aristóteles, onde se diz que todos os que se tornaram famosos por qualquer faculdade eram melancólicos. Nisso, ele confirmou a noção platônica expressa no livro De scientia, de que as pessoas mais inteligentes são propensas ao furor e loucura". ${ }^{65}$ Ficino mobiliza passagem do Fedro (245a), onde Platão afirma que sem a loucura, de nada valeria "alcançar as portas das Musas, na expectativa de ser um bom poeta adquirindo conhecimento da arte". ${ }^{66} \mathrm{E}$ complementa: "de acordo com os médicos, uma loucura de tal tipo não é incitada em alguém que não seja melancólico". ${ }^{67}$ Ficino conclui dizendo que "se deve dar razão a Demócrito, Platão e Aristóteles quando afirmam que não são poucos os melancólicos que às vezes excedem a todos em inteligência, e que parecem não ser humanos, mas divinos". ${ }^{68}$

Embora distingam a compreensão da melancolia como força intelectual, capaz de atrair o pensamento para o centro das coisas - como sustenta Ficino em De Vita Sana ${ }^{69}$ - de seu entendimento como "condição emocional subjetiva" ${ }^{\text {", }}$, não fica claro o que os autores de Saturno e a melancolia querem dizer quando falam em "pauta intelectual do gênio moderno", associada ao nascimento de uma "nova consciência humanista" produzida em "atmosfera de contradição intelectual", onde o "auto-suficiente 'homo literatus', ao ocupar sua posição, se via desgarrado entre os extremos da auto-afirmação, às vezes elevada à hybris, e a dúvida de si, que às vezes incidia em desespero". ${ }^{71}$ Homens de letras, pintores, escultores, poetas: uma "prematura" consciência de tragicidade e deslocamento parece ter favorecido, segundo os autores de Saturno e a melancolia, o surgimento de um ideal cultural elevado, sedimentado na noção de gênio. Em Idea, texto de Panofsky escrito na década de 1920 - ou seja, relativamente contemporâneo a Saturno e a 
melancolia -, encontramos uma passagem que pode ajudar no esclarecimento do significado da referida pauta intelectual do gênio moderno: "A teoria da arte do Renascimento, vinculando assim a produção da Idéia à visão da natureza, e situando-a doravante numa região que, sem ser ainda a da psicologia individualista, já não era a da metafísica, dava o primeiro passo em direção ao reconhecimento daquilo que nos habituamos a chamar de 'Gênio'”. ${ }^{72}$ Em estudo voltado para a compreensão da "evolução do conceito de Belo", não é de se estranhar uma certa teleologia. Trata-se do "primeiro passo" em direção à genialidade moderna, assertiva que parece alimentar a importante discussão, desde meados do século XIX recorrente em alguns dos mais originais historiadores da arte e da cultura interessados no período conhecido como Renascimento: como, a partir do que Burckhardt chamou de "redespertar da Antiguidade" e Aby Warburg de "reviver do paganismo"73, chegou-se a uma concepção das artes e do fazer artístico que, sem questionar o primado da unidade entre ética, retórica e poética o bom, o belo e o que convém -, estabeleceu, com ferramentas conceituais antigas, alguns dos alicerces da moderna teoria da arte, sistematizados apenas no século XVIII por autores como Winckelmann e Lessing?

Se a intuição do sentido de genialidade nos escritos de Ficino for de fato indício de uma certa tragicidade moderna, ainda que incipiente, tal modernidade é construída a partir de alicerces fincados na Antiguidade: a teoria dos humores, a noção aristotélica de homem diferenciado, a idéia platônica de furor divino, a astrologia e a magia hermética. A despeito das especulações de Panofsky, Saxl e Klibansky, Ficino não oferece propriamente uma teoria ou reflexão sobre o gênio, e sim sobre as inclinações do homem de letras melancólico de inspiração saturnina, o que não é pouca coisa para a compreensão do temperamento como elemento decisivo capaz de impregnar a obra do artífice de valor próprio, particular e diferenciado. Ficino, assim, não apenas elaborou uma teoria do Belo indissociável do Bem, com lugar de destaque ao Amor, como associou a produção do Belo, nas mais diversas artes, ao furor divino e ao temperamento melancólico, ao espírito perscrutador, à procura do centro das coisas, à capacidade de ver além do visível e transcender o fenômeno, numa atração simpática exercida pela verdade. A beleza de uma pintura, de uma escultura, deve-se, assim, mais à Idéia, tornada visível pela combinação de engenho e capacidade de enxergar além das aparências, que às teorias clássicas do decoro, harmonia e proporção. Não que estas sejam rejeitadas; elas são tratadas, todavia, como resultado visível de uma beleza incorpórea, cujo poder de atração nada mais é que o desejo de unir-se a Deus.

Como comprovam os importantes estudos iconográficos de André Chastel, Edgar Wind, Erwin Panofsky e muitos outros, a combinação de tais elementos marcou profundamente a produção artística do período. ${ }^{74}$ Tome-se, apenas como exemplo, o caso de Amor Sagrado e Amor Profano, composição de Tiziano, onde, segundo Panofsky, "as suas figuras não exprimem um contraste entre o bem e o mal: simbolizam um princípio em dois modos existência e dois graus de perfeição"75, a saber, a Vênus Vulgar e a Vênus Celestial, como pensadas por Ficino em seu comentário ao Banquete de Platão. ${ }^{76}$ Ainda 
segundo Panofsky, "o fato de Cupido estar colocado entre as duas Vênus, embora um pouco mais perto da 'terrestre' ou 'natural' e de agitar a água da fonte pode exprimir a crença neoplatônica de que o amor, um princípio de 'mistura' cósmica, atua como um intermediário entre o céu e a terra". ${ }^{77}$ Também Michelangelo mostrou conhecer os mistérios do neoplatonismo e do hermetismo, assim como Rafael e outros.

Que as arti liberali transformaram-se profundamente nos séculos XV e XVI parece ter sido consenso entre os próprios homens do Renascimento; contudo, projetar em tais transformações valores contemporâneos (ou, melhor dizendo, valores contemporâneos a uma contemporaneidade que já ficou para trás), ver nos séculos $X V$ e $X V I$ inícios e modernidades incipientes, é manter a História da Arte presa ao evolucionismo oitocentista e alheia a importantes questões da crítica historiográfica dos últimos cinqüenta anos. Ao mesmo tempo, reduzir a História da Arte a um inventário de práticas e representações historicamente verossímeis é subsumi-la a uma forma de História Cultural que, há algum tempo, vem mostrando sinais de esgotamento.

\section{* Felipe Charbel Teixeira é doutor em História Social da Cultura pela PUC/RJ e pós- doutorando em Letras Vernáculas na USP.}

Este trabalho contou com auxilio financeiro da FAPESP.

${ }^{1}$ FICINO, M. De Amore. Milano: SE, 2003, II, 2, p. 29. "La Bellezza adunque la quale per sua natura a sé tira le cose, sta tra la Bontà e la Giustizia: e certamente dalla Bontà nasce e va alla Giustizia".

2 Conferir: KOSSOVITCH, L. "Contra a idéia de Renascimento". In: NOVAES, A. (org.). Artepensamento. São Paulo: Companhia das Letras, 2006.

${ }^{3}$ Este sentido fazia-se presente em diversos escritos italianos do período. Conferir: CHABOD, F. "The Concept of the Renaissance". In: Machiavelli and the Renaissance. New York, Evanston and London: Harper Torchbooks, 1958, p. 152; HUIZINGA, J. “El problema del Renacimiento". In: El concepto de la historia. México: Fondo de Cultura Económica, 1994, pp. 101-155. Para uma discussão da circularidade assimétrica das formas e costumes, conferir: TEIXEIRA, F. C.. Timoneiros: retórica, prudência e história em Maquiavel e Guicciardini. Rio de Janeiro, Tese de Doutorado, PUC-Rio, 2008, pp. 21-54.

${ }^{4}$ KLEIN, R. A forma e o inteligível. São Paulo: Edusp, 1998, p. 332.

${ }^{5}$ A referência obrigatória é o famoso artigo de Gombrich sobre a idéia de progresso nas artes no Renascimento. Conferir: GOMBRICH, E.H. "A concepção renascentista de progresso artístico e suas conseqüências”. In: Norma e Forma. São Paulo: Martins Fontes, 1990.

${ }^{6}$ Para um aprofundamento dessas questões, conferir: TEIXEIRA, F. C. Timoneiros: retórica, prudência e história em Maquiavel e Guicciardini. Op. cit., pp. 21-54.

${ }^{7}$ VASARI, G. Le vite de'più eccellenti pittori scultori ed architettori, vol. 2. Firenze: G.C. Sansoni, 1878, p. 96. "Questa lode certo è tocca alla terza etì; nella quale mi par potere dir sicuramente, che l'arte abbia fatto quello che ad una imitatrice della natura è lecito poter fare; e che ella sia salita tanto alto, che più presto si abbia a temere del calare a basso, che sperare oggimai più augumento". 
${ }^{8}$ Emprego a categoria "verossímil histórico" como sugerida em: PÉCORA, A. Máquina de Gêneros. São Paulo: EdUSP, 2001, pp. 11-16.

${ }^{9}$ BURCKHARDT, J. A cultura do Renascimento na Itália. São Paulo: Companhia das Letras, 2003, p. 118.

${ }^{10}$ Sobre esta questão, afirma Carlos Antônio Leite Brandão: "Tanto Burckhardt, em meados do século passado, como Garin, atualmente, fazem de Alberti emblema do Renascimento. Mas, o que se entende como Renascimento para estes autores, para darmos apenas um exemplo, são interpretações tão discordantes como as de Alberti feitas por eles. Em Burckhardt, Alberti é o precursor de Leonardo da Vinci, o protótipo do homem universal, senhor de todas as suas possibilidades, representante da geração cuja ciência, cultura e razão haviam vencido o 'obscurantismo' medieval. Em Garin, ao contrário, Alberti reflete toda a crise que estas mesmas ciência, cultura e razão vivem no século XV". BRANDÃO, C. A. L. Quid Tum? O combate da arte em Leon Battista Alberti. Belo Horizonte: Editora UFMG, 2000, p. 29.

${ }^{11}$ GARIN, E. "Interpretações do Renascimento". In: Idade Média e Renascimento. Lisboa: Editorial Estampa, 1994, p. 83.

12 Ibidem, p. 84.

${ }^{13}$ Ibidem, p. 85. Grifos no original.

${ }^{14}$ Cf. Ibidem, p. 86. "A tristeza de Alberti, que não é, repare-se, uma concepção pessimista bem articulada, alimenta-se na consciência de uma situação de mudança”.

15 Ibidem, p. 84.

16 Proposto em 1925 por Hans Baron, em artigo publicado na revista Historische Zeitschrift, o termo "humanismo cívico" adquiriu destaque nos estudos sobre o século XV, especialmente nos escritos de Eugenio Garin e John Pocock. Desenvolvido com maiores detalhes em The Crisis of the Early Italian Renaissance, livro publicado em 1955, a categoria engloba três elementos decisivos, a saber: (a) a noção de governo popular; (b) patriotismo e (c) valorização do serviço público e comprometimento com a República. Baron apresenta, ainda, a famosa (e polêmica) tese sobre origem do "humanismo cívico", centrada nos conflitos de fins do século XIV e início do XV, que culminaram com a vitória da república florentina sobre as forças milanesas comandadas pelo duque Giangaleazzo Visconti. Segundo o historiador alemão, teria emergido entre os florentinos, durante os anos de agitação que marcaram a passagem do trezentos para o quatrocentos, uma nova consciência cívica, tornada possível graças à resistência dos florentinos às forças militares milanesas. Além disso, o "humanismo cívico" caracterizou-se, na visão de Baron e seus seguidores, por uma ruptura com o humanismo retórico e supostamente apolítico do século XIV, pela gênese delimitada historicamente na guerra contra Milão, e por uma identificação total entre os textos humanistas e a realidade republicana florentina. Conferir: HANKINS, J. (org.). Renaissance Civic Humanism. Cambridge: Cambridge University Press, 2001, pp. 1-13.

17 Conferir: KRISTELLER, P. O. Renaissance Thought ans its Sources. New York: Columbia University Press, 1979, p. 22.

18 Sobre a educação no Renascimento, conferir: WARD, J. "Renaissance Commentators on Ciceronian Rhetoric". In : MURPHY, J. J. (org.). Renaissance Eloquence. Studies in the Theory and Practice of Renaissance Rhetoric. Berkeley, Los Angeles and London: University of California Press, 1983; GARIN, E. L'eduzacione umanistica in Italia. Bari: Laterza, 1953; RICE JR., E. F. "Foreword". In: Vittorino da Feltre and Other Humanist Educators. Toronto, Buffalo and London: University of Toronto Press, 1996.

${ }^{19}$ BRUNI, L. De studiis et litteris liber. Traduzido para o italiano por Eugenio Garin. In: GARIN, E. L'eduzacione umanistica in Italia. Op. cit., p. 29. "Per chi voglia giungere a quella eccellenza, alla quale io ora ti chiamo, ritengo innanzitutto necessaria una perizia negli studi letterari non piccola né volgare, mas grande e costante e accurata e profonda". 
${ }^{20}$ Conferir: VITI, P. Leonardo Bruni e Firenze. Studi sulle lettere pubbliche e private. Roma: Bulzoni Editore, 1992, especialmente pp. 311-363.

${ }^{21}$ BRUNI, L. De studiis..., p. 30. "Di tal diligenza nostra II punto principale consiste nel fare in modo da leggere soltanto i libri che siano stati scritti dagli ottimi autori latini, gurdandoci invece da quelli scritti male rozzamente, como da una calamitosa rovina del nostro ingegno".

${ }^{22}$ No livro II do diálogo De Oratore, Cícero, logo na abertura, em passagem dirigida a Quinto, seu irmão, afirma que "a eloqüência alcançada por Crasso e Antônio", os dois protagonistas da conversação, "nunca poderia se realizar sem o conhecimento de todas as coisas que produziram a prudência e a fluência oratória [dicendi copiam] manifesta nos dois". CICERO, Marco Tulio. De Oratore, II, 2. Cambridge and London: Harvard University Press, 2001. A idéia de orador pleno pode ser resumida na expressão, cunhada por Quintiliano, vir bonus dicendi peritus. Ainda sobre esta questão, conferir: NARDUCCI, E. Cicerone e l'eloquenza romana. Retorica e progetto culturale. Bari: Laterza, 1997.

${ }^{23}$ De ingenuis moribus. Traduzido para o italiano por Eugenio Garin. In: GARIN, E. L'eduzacione umanistica in Italia. Op. cit., p. 59. "É in quella verde etá, dunque, che si devono gettare le fondamenta di tutto il nostro vivere, ed informare l'animo a virú finché sia tenero e capace di ricevere qualunque impronta, la quale, come allora sará fatta, cosí durerá per tutta la nostra vita avvenire".

24 "Grandissima comoditade arrecano le lettere universalmente a tutti coloro che di quelle piglian diletto, ma molto maggiore la apportano elle senza alcuna comparazione a gli scultori, a' pittori et a gli architetti, abbellendo et assottigliando (come elle fanno) le invenzioni, che naturalmente nascono in quelli".

25 "Il che è veramente la piú utile e la piú necessaria cosa che advenir possa a gli ingegni miracolosi di questi artefici; oltra che il giudizio non può essere molto perfetto in una persona".

26 "Chi non conosce che e' bisogna con matura considerazione sapere, o fugire, o apprendere, per sé solo, ciò che si cerca mettere in opra, senza avere a raccomandarsi alla mercé della altrui teorica, la quale separata da la pratica il piú delle volte giova assai poco? Ma quando elle si abbattono per avventura a essere insieme, non è cosa che piú si convenga alla vita nostra; sí perché l'arte co 'I mezzo della scienzia diventa molto piú perfetta e piú ricca".

${ }^{27}$ GUICCIARDINI, F. Ricordi Diari Memorie. Editori Riuniti, 1981, p. 181, máxima 35. "Quanto è diversa la pratica dalla teorica! quanti sono che intendono le cose bene, che o non si ricordono o non sanno metterle in atto! $\mathrm{E}$ a chi fa così, questa intelligenza è inutile, perché è come avere uno tesoro in una arca con obligo di non potere naus tralo fuora".

28 "E che questo sia il vero, manifestamente si vede in Leonbatista Alberti fiorentino, il quale, per avere atteso alla lingua latina, e dato opera alla architettura, alla prospettiva et alla pittura, lasciò i suoi libri scritti in maniera che, per non essere stato fra gli artefici moderni chi le abbia saputo distendere con la scrittura, ancora che infiniti ne abbiamo avuti piú eccellenti di lui nella pratica, e' si crede communemente (tanta forza hanno gli scritti suoi nelle bocche de' dotti) che egli abbia avanzato tutti coloro che lo avanzarono con l'operare".

29 "E vedesi per il vero quanto a lo accrescere la fama et il nome, che fra tutte le cose gli scritti sono e di maggior forza e di maggior vita; atteso che i libri agevolmente vanno per tutto, e per tutto si acquistan fede; purché e' siano veritieri e senza menzogne".

${ }^{30}$ CICERO, Marco Tulio. Orator / El Orador, I, 71. Madrid: Alianza Editorial, 2004.

${ }^{31}$ Conferir: KAHN, V. Rhetoric, Prudence and Skepticism in the Renaissance. Ithaca and London: Cornell University Press, 1985, p. 40.

${ }^{32}$ Como na passagem: "Ché invero leggendo le istorie e le favole et intendendole, un capriccioso maestro megliora continovamente; e fa le sue cose con piú bontà e con maggiore intelligenzia che non fanno gli illiterati”. 
33 Sobre a perspectiva, conferir o clássico estudo de Erwin Panofsky: PANOFSKY, E. La perspectiva como "forma simbolica". Barcelona: Tusquets Editor, 1973.

${ }^{34}$ Conferir: KOSSOVITCH, L. "Contra a idéia de Renascimento". Op. cit., p. 67. "A partir dos anos 20, a perspectiva ergue-se sozinha nos estudos de 'Renascimento'; contribui para o isolamento o horizonte cubista e abstracionista da arte contemporânea. Separa-se a perspectiva das proporções, assim, da simetria, anacronismo de historiadores alheios à Retórica: ficando-se em $D a$ Pintura, a perspectiva não é exposta nele senão como parte de parte da pintura, da 'composição', retoricamente ordenada, e não como assunto isolável, que se tenha por principal".

${ }^{35}$ ALBERTI, Da Pintura, II, p. 53. "La maggior opera che faccia il Pittore, non è una statua grande quanto un colosso, ma è una storia: conciossiachè si trova maggior lode d'ingegno in un'istoria, che in un colosso".

${ }^{36}$ ALBERTI, Da Pintura, II, p. 45. "Imperocchè ingegnandosi la Pittura di rappresentarci le cose veduti, consideriamo in che modo esse cose veghino alla veduta nostra. Principalmente quando noi squadriamo qualche cosa, noi veggiamo quella cosa esser un certo che, che occupa luogo. E il Pittore circonscriverà la spazio di questo luogo; e questo modo del tirare i dintorni con vocabolo conveniente chiamerà circonscrizione".

${ }^{37}$ BRANDÃO, C. A. L. Quid Tum? O combate da arte em Leon Battista Alberti. Op. cit., p. 157.

${ }^{38}$ ARGAN, G. C. História da arte italiana, vol. II. De Giotto a Leonardo. São Paulo: Cosac \& Naif, 2003, p. 130.

39 Ibidem, p. 132.

${ }^{40}$ ALBERTI. Da Pintura, II, p. 60. "Ma l'istoria che ragionevolmente sia da lodare e guardare con maraviglia, bisogna che sia tale che con alcuni allettamenti si dimostri esser tanta dilettevole ed ornata, che intrategna lungamente gli occhi di coloro che sano, e di quei che non sanno, con piacere, e con dilettazione dell'animo".

${ }^{41}$ Trata-se de preceito da retórica antiga amplamente difundido no Renascimento. Como exemplo aleatório, cito uma passagem do Dialogo della Rettorica de Sperone Speroni, composto na primeira metade do século XVI: "[...] sendo ufficio dell'Oratore II persuader gli ascoltanti dilettando, insegnando, et movendo [...]". SPERONI, S. Dialogo delle lingue e Dialogo della Rettorica. R. Carabba Editore, 1912, p. 90.

${ }^{42}$ ALBERTI. Da Pintura, II, p. 54. "Adunque in questo componimento delle superficie bisogna andar investigando gandemente la grazia e la bellezza. Ma in che modo noi possiamo ottener questo, io non ho trovato via più certa, che andar a considerare la natura stessa, e però guardiamo diligentissimamente e per lungo tempo, in che modo la natura maravigliosa artefice delle cose, abbi composte le superficie nelle belissime membra. Nello imitare la quale bisogna esercitarsi con tutti i pensieri e diligenze nostre [...]".

${ }^{43}$ Conferir: BRANDÃO, C. A. L. Quid Tum? O combate da arte em Leon Battista Alberti. Op. cit., p. 158.

${ }^{44}$ Conferir: PANOFSKY, E. Idea: a evolução do conceito de belo. São Paulo: Martins Fontes, 2000, p.47.

${ }^{45}$ VASARI, G. Le vite de'più eccellenti pittori scultori ed architettori, vol. 2. Op. cit., p. 288. "E quanto alla maniera buona delle pitture, a Masaccio massimamente, per aver egli, come disidevoso di acquistar fama, considerato (non essendo la pittura altro che un contraffar tutte le cose della natura vive, col disegno e concolori semplicemente, come ci sono prodotte da lei) che colui che ciò più perfettamente consegue, si può dire eccellente".

${ }^{46}$ Ibidem. "perchè invero le cose fatte innanzi a lui si possono chiamar dipinte, e le sue vive, veraci e naturali, allato a quelle state fatte dagli altri".

47 Ibidem. "il che è stato di grande utile agli artefici, e ne merita esser commendato, come se nefusse stato inventore" 
${ }^{48}$ ARGAN, G. C. História da arte italiana, vol. II. De Giotto a Leonardo. Op. cit., p. 183.

49 Conferir: KRISTELLER, P. O. Eight Philosophers of the Renaissance. Stanford: Stanford University Press, 1964, pp. 37-53.

${ }^{50}$ Conferir: YATES, F. Giordano Bruno e a tradição hermética. São Paulo: Cultrix, 1995, pp. 13-31.

${ }^{51}$ FICINO, M. De Amore. Op. cit., II, III, p. 32. "L'unico centro di tutte le cose è Dio. I quattro cerchi che d'intorno a Dio continovamente si rivolgono, sono la Mente, l'Anima, la Natura e la Materia".

52 PANOFSKY, E. "O movimento neoplatônico em Florença e no Norte da Itália". In: Estudos de Iconologia. Temas humanísticos na arte do renascimento. Lisboa: Editorial Estampa, 1982, p. 121.

53 Ibidem.

${ }^{54} \mathrm{FICINO}, \mathrm{M}$. De Amore, II, III, p. 34. "La Bontà di tutte le cose è uno Dio, per il quale tutte son buone: la Belezza è il raggio di Dio, infuso in que' quattro cerchi, che intorno a Dio si rivolgono".

${ }^{55}$ Ibidem. "Questo raggio dipinge in questi quattro cerchi, tutte le spezie di tutte le cose: e noi chiamiamo quelle spezie, nella Mente Angelica, idee: nell'Anima, ragioni: nella Natura, semi: e nella Materia, forme".

${ }^{56}$ Ibidem. II, II, p.30. "Si che um cerchio solo, è quel medesimo da Dio nel Mondo, e da il Mondo in Dio: e in tre modi si chiama. In quanto ei comincia in Dio e alletta, Bellezza: in quanto ei passa nel Mondo e quel rapisce, Amore: in quanto, in mentre che ei ritorna nello Autore, a lui cominciando da la Bellezza, termina in delettazione".

57 Ibidem. V, III, p. 72. "Sono alcuni, che hanno oppenione, la Pulcritudine essere una certa posizione di tutti i membri, o veramente commensurazione e proporzione, con qualche suavità di colori: l'oppenione de'quali noi non ammettiamo".

${ }^{58}$ Conferir: PLOTINO. Tratado das Enéadas. São Paulo: Polar Editorial, 2002, p. 21. "Se nos voltarmos para as belas condutas e os belos discursos, poderemos atribuir a causa de sua beleza à simetria? É possível falar de simetria no que diz respeito às condutas nobres, às leis, ao conhecimento ou às ciências? As teorias ou especulações podem ser simétricas umas em relação às outras? Se uma concordância entre elas faz com que sejam simétricas, também pode haver concordância entre teorias más".

${ }^{59}$ FICINO, M. De Amore. Op. cit., V, III, p. 71. "Imperocché benché noi chiamiamo alcuni corpi belli, non sono però belli per la loro materia".

${ }^{60}$ Ibidem, p.72. "perché all'Animo piace la specie di alcuna persona, non in quanto nella giace nella esteriore Materia, ma in quanto la immagine di quella per II senso vedere, dallo animo si piglia”.

${ }^{61}$ Ibidem. "Adunque la spezie incorporale è quella che piace: e quello che piace, è grato: e quello che è grato, è bello. Di qui si conchiude, che lo amore a cosa incorporale si riferisce: e essa Bellezza è più tosto una certa spirituale similitudine della cosa, che spezie corporale".

62 PANOFSKY, E. Idea: a evolução do conceito de belo. Op. cit., pp. 56-57.

${ }^{63}$ FICINO, M. De Amore. Op. cit., III, III, p. 50. "Resta dopo questo dichiarare como l'Amore è maestro e signore di tutte le Arti. Noi intenderemo lui esser maestro delle Arti, se considereremo nessuno potere arte alcuna trovare o imparare, se non mosso da diletto di ricercare il vero, e se chi insegna non ama i discepoli e se i discepoli non portano amore a tal dottrina".

${ }^{64}$ Conferir: KLIBANSKY, R; PANOFSKY, E; SAXL, F. Saturno y la melancolía. Madrid: Alianza Editorial, 2004, p. 250. "Marsilio fue mucho más allá de las observaciones dispersas de otros autores y dedicó una monografía completa a la nueva doctrina. Fue él quien realmente dio forma a la idea del hombre genial melancólico y se la reveló al resto de Europa - en particular a los grandes ingleses de los siglos XVI y XVII - en el claroscuro mágico del misticismo neoplatónico cristiano". 
${ }^{65}$ FICINO, M. Three Books on Life / De vita libri tres. Edição bilíngue. New York: The Renaissance Society of America, 1989, I, V, p. 117.

${ }^{66}$ PLATÃO. Fedro, 245a. In: Diálogos socráticos. Bauru: Edipro, 2008.

${ }^{67}$ FICINO, M. Three Books on Life / De vita libri tres. Op. cit., I, V, p. 117.

68 Ibidem.

${ }^{69}$ Em De Vita Sana, primeiro dos três livros de De Vita libri tres, Ficino argumenta que o humor melancólico possuía afinidade com o centro da Terra, em função de seu caráter frio e seco. Do mesmo modo, associada a Mercúrio e Saturno, a melancolia é relacionada por Ficino à "procura do centro de todos os assuntos". Ibidem, I, V, p. 121.

${ }^{70}$ KLIBANSKY, R; PANOFSKY, E; SAXL, F. Saturno y la melancolía. Op. cit., p. 239.

${ }^{71}$ Ibidem, pp. 243-244.

${ }^{72}$ PANOFSKY, E. Idea: a evolução do conceito de belo. Op. cit., p. 67.

${ }^{73}$ Para uma análise dessa categoria, central no pensamento de Warburg, conferir: GOMBRICH, E. H. "The Nineteenth Century Notion of a Pagan Revival". In: WOODFIELD, R. Art History as Cultural History. Amsterdam: G+B Arts, 2001.

${ }^{74}$ Conferir: CHASTEL, A. Fables, formes, figures I. Paris: Flammarion, 2000; WIND, E. Pagan Mysteries in the Renaissance. New York and London: The Norton Library, 1968; PANOFSKY, E. "O movimento neoplatônico em Florença e no Norte de Itália". Op. cit.

${ }^{75}$ PANOFSKY, E. "O movimento neoplatônico em Florença e no Norte de Itália". Op. cit., p. 130.

${ }^{76}$ Conferir: FICINO, M. De Amore. Op. cit., II, VII, pp. 38-40.

${ }^{77}$ PANOFSKY, E. "O movimento neoplatônico em Florença e no Norte de Itália". Op. cit., p. 131. 